\title{
Quality of life of people with schizophrenia, bipolar disorder and other psychotic disorders ${ }^{\dagger}$
}

\author{
Samuli I. Saarni, Satu Viertiö, Jonna Perälä, Seppo Koskinen, Jouko Lönnqvist \\ and Jaana Suvisaari
}

\section{Background}

Health utility and quality of life (QOL) are increasingly important outcome measures in healthcare and health economics.

\section{Aims}

To compare the loss of subjective QoL and utility-based health-related quality of life (HRQOL) associated with psychotic disorders.

\section{Method}

A representative sample of 8028 Finns was screened for psychotic disorders and bipolar I disorder. Lifetime psychotic disorders were diagnosed using the Structured Clinical Interview for DSM-IV and/or case records. Health-related quality of life was measured with EQ-5D and 15D, and QoL was measured with a 10-point scale.

\section{Results}

Schizoaffective disorder was associated with the largest losses of QoL and HRQOL, with bipolar I disorder associated with similar or smaller losses than schizophrenia. Current depressive symptoms explained most of the losses.

\section{Conclusions}

Depressive symptoms are the strongest predictors of poor QoL/HRQoL in psychotic disorders. Subjective loss of QoL associated with psychotic disorders may be smaller than objective loss of functioning suggests. The EQ-5D is problematic as an outcome measure in psychotic disorders.

\section{Declarations of interest} None.
Quality of life (QoL) is becoming an increasingly important outcome of healthcare for several reasons. Subjective valuations, autonomy and the needs of patients are increasingly respected. Generic measures are needed to directly compare the burden of different conditions and treatments. Health policy and economic evaluations favour quality-adjusted life-years (QALYs) ${ }^{1}$ that can be based on health-related quality of life (HRQoL) measures. With psychotic disorders, deinstitutionalisation has further emphasised the importance of optimising functional status. Positive psychotic symptoms, the traditional target of antipsychotic drug treatment, are not strong determinants of either ability to function or QoL. ${ }^{2-5}$

Psychotic disorders are a heterogeneous group, and comparisons of disorders using generic QoL/HRQoL are scarce. Most studies on QoL/HRQoL and psychotic disorders have investigated selected clinical samples, so information on the severity of these disorders in the general population is lacking. Which symptoms determine QoL/HRQoL is also poorly known. Using a representative population sample, we investigated:

(a) the comparative burden of different functional psychotic disorders on QoL/HRQoL;

(b) how different disorders decrease subjective QoL relative to utility-based HRQoL, and which dimensions of HRQoL are influenced;

(c) the correlation between different psychotic symptoms, depression, clinician-assessed outcome and QoL/HRQoL.

\section{Method}

\section{Health 2000 survey}

The data come from the Health 2000 survey, a representative study of the Finnish population aged 30 and over, and its substudy Psychoses in Finland. The methods and basic results of the Health

'See pp. 348-349, this issue
2000 survey have been published previously ${ }^{6}$ (available at www.terveys2000.fi/indexe.html). Briefly, the survey had a twostage, stratified cluster sampling design. The original sample included 8028 people, with double-sampling of people over 80 years of age, giving a response rate of $93 \%$ for any part of the survey. The survey consisted of a health interview, a thorough health examination, laboratory tests, a structured mental health interview (the Munich version of the Composite International Diagnostic Interview, CIDI) ${ }^{7}$ and several self-report questionnaires. The data were collected between August 2000 and July 2001.

\section{Psychiatric diagnostics}

The Psychoses in Finland study methodology has been described in detail previously. ${ }^{8}$ People from the Health 2000 survey were included in the Psychoses in Finland study if they reported ever having had a psychotic disorder, were diagnosed by the physician conducting the health examination to have a definite or probable psychotic disorder, or had a lifetime history of psychotic or manic symptoms in the CIDI interview. Register-based screening was also used, covering hospital treatments in Finland for psychotic disorders, free antipsychotic medication, mood-stabilising medication use without diagnosis of a relevant somatic disorder or disability pension because of a psychotic disorder. As CIDI is not reliable in diagnosing psychotic disorders, people identified using CIDI were re-interviewed with the Research Version of the Structured Clinical Interview for DSM-IV (SCID-I). ${ }^{9}$ All case notes from hospital and out-patient treatments were collected, even from those who were not interviewed. The ethics committees of the National Institute for Health and Welfare (former National Public Health Institute) and the Hospital District of Helsinki and Uusimaa approved the studies. Participants provided written informed consent. Three experienced clinicians (J.P., J.S. and S.I.S.) made the final best-estimate lifetime DSM-IV diagnoses based on a systematic evaluation of all available data. The Kappa values between the raters ranged from 0.74 to 0.97 for different psychotic disorders, and were either good or excellent regardless 
of whether the diagnosis was based on both the SCID-I interview and case records or on case records alone. ${ }^{8}$

Lifetime diagnoses of psychotic disorders were classified into schizophrenia, other non-affective psychosis (including schizoaffective disorder, schizophreniform disorder, delusional disorder, brief psychotic disorder and psychotic disorder not otherwise specified) and affective psychosis (major depressive disorder with psychotic features and bipolar I disorder). The main focus of this study was on these groups, but we also examined separately the most common individual psychotic disorders (Table 1). This study considers lifetime disorders that had their onset before participants completed the QoL/HRQoL questionnaires as part of the Health 2000 study.

\section{Health-related and subjective quality-of-life measurement}

Health-related quality of life is the part of QoL that can potentially be influenced by health and healthcare. As there is no gold standard for HRQoL measurement, ${ }^{10,11}$ we used two wellestablished, generic self-report preference-based HRQoL measures: the EQ-5D ${ }^{12}$ and the $15 \mathrm{D} .{ }^{13}$

Preference-based HRQoL questionnaires include several dimensions that can be summarised as a single score using utility theory and preferences elicited from the population. The result is a quantitative measure of the severity of health states as people value them, referred to as health utility. Health utilities range from 0 , being equal to death, and 1 , which is perfect health. They form the quality-component of QALYs, which combine length and quality of life into a single metric. ${ }^{14}$ For example, the National Institute for Health and Clinical Excellence uses QALYs as their preferred outcome measure in cost-effectiveness analyses. ${ }^{1}$

The $15 \mathrm{D}^{13,15,16}$ has 15 dimensions with five categories of severity: mobility, vision, hearing, breathing, sleeping, eating, speech, elimination, usual activities, mental function, discomfort and symptoms, depression, distress, vitality and sexual activity (www.15d-instrument.net). The $15 \mathrm{D}$ utility index ${ }^{15}$ ranges between 1 (full health) and 0 (death). We included participants with 12 or more completed 15D dimensions, imputing missing values as recommended. ${ }^{13}$ Changes of over $0.02-0.03$ points on the $15 \mathrm{D}$ are considered clinically important. ${ }^{16}$ The EQ-5D ${ }^{12,17,18}$ has five dimensions with three categories of severity: mobility, self-care, usual activities, pain or discomfort, and anxiety or depression (www.euroqol.org). The EQ-5D UK time trade-off index ${ }^{19}$ ranges between 1 (full health) and -0.59 ( 0 is death). A time trade-off index is based on hypothetical trade-offs between length of life and symptoms. Only participants who fully completed the EQ-5D questionnaire were included. Although there is no unequivocally agreed threshold for a minimum clinically important change on the EQ-5D, thresholds of 0.07 points have been observed. ${ }^{20}$

Both the 15D and EQ-5D enquire about the health state of the respondent 'today'. The $15 \mathrm{D}$ compares favourably with similar HRQoL instruments in most of the important properties. $^{13,15,16,21,22}$ Although EQ-5D is among the most extensively evaluated HRQoL measure, ${ }^{23}$ it is problematic in general population samples due to its low sensitivity in detecting deviations from full health. ${ }^{11}$

Whereas the HRQoL instruments used require answers to a predefined set of questions concerning symptoms and functioning, the subjective QoL here means global life satisfaction as defined by the respondent. Subjective QoL was measured by asking the respondents to rate their current QoL as a whole, over the past 30 days, on a visual-analogue scale (VAS) from 0 to 10 , anchored at best and worst possible QoL.

\section{Sociodemographic variables, somatic conditions and depressed mood}

Data on sociodemographic variables and chronic somatic diseases were collected using structured interviews at home or institution. As the relationship between HRQoL and age is not linear, age was categorised as 30-44, 45-54, 55-64, 65-74, 75-85 and over 85 years. Education was categorised as basic, secondary or higher. Household income, derived from registers on taxes and welfare benefits, was adjusted for family size ${ }^{24}$ and divided into quintiles. Marital status was classified into two categories: married or cohabiting, and others. Chronic somatic conditions were diagnosed by asking, separately for each condition, whether the participant had ever been diagnosed by a physician with one of the 25 included conditions. ${ }^{11}$ Depressed mood was assessed with the Beck Depression Inventory (BDI). ${ }^{25}$

\section{Symptom measures}

For lifetime symptoms of psychotic disorders, we used the Major Symptoms of Schizophrenia Scale (MSSS) ${ }^{26,27}$ and some global ratings from the Scale for the Assessment of Positive Symptoms (SAPS) ${ }^{28}$ and from the Scale for the Assessment of Negative Symptoms (SANS). ${ }^{29}$ These were completed based on the SCID-I interview and all medical records on a lifetime basis. ${ }^{30}$

The symptoms in the MSSS are rated from 1, clearly not present, to 5, severe; the symptoms in the SANS and SAPS are coded on a six-point scale, ranging from 0 , not at all, to 5 , severe. The following symptom and course ratings were used in the analysis: hallucinations, delusions, positive formal thought disorder, catatonia, affective deterioration, negative formal thought disorder, depression, mania, course and outcome. From these ratings, we formed summary scores for positive symptoms (delusions and hallucinations), disorganised symptoms (positive thought disorder and bizarre behaviour) and negative symptoms (negative thought disorder, avolition-apathy, anhedonia-asociality and affective deterioration).

\section{Statistical methods}

To analyse non-response, we investigated whether people with psychotic disorders who completed the QoL/HRQoL measures differed from non-responders using information from the ratings for psychotic symptoms. The following symptom and course ratings were used in the analysis: hallucinations, delusions, positive formal thought disorder, catatonia, affective deterioration, negative formal thought disorder, depression, mania, course and outcome. Differences between responders and non-responders were tested with the Kruskal-Wallis test. The following groups were investigated: schizophrenia, other non-affective psychosis and affective psychoses. From the latter two groups, schizoaffective disorder, delusional disorder, bipolar I disorder and major depressive disorder with psychotic features were investigated separately.

To estimate the association between different disorders and loss of HRQoL or QoL, we created separate multiple regression models using each of the instruments (15D, EQ-D, QoL) as dependent variables. To estimate the effects covariates, we created three sets of regression models in a stepwise manner: the first model controlled for age and gender, the second added education, income and marital status, and the third the 25 somatic conditions. To estimate the effect of depression, we added a fourth model with BDI. The covariates were entered as dummy variables except for BDI, which was entered as a continuous variable. Linear regression for survey data was used to analyse subjective QoL. As the HRQoL measures have a ceiling effect $55.4 \%$ of respondents 


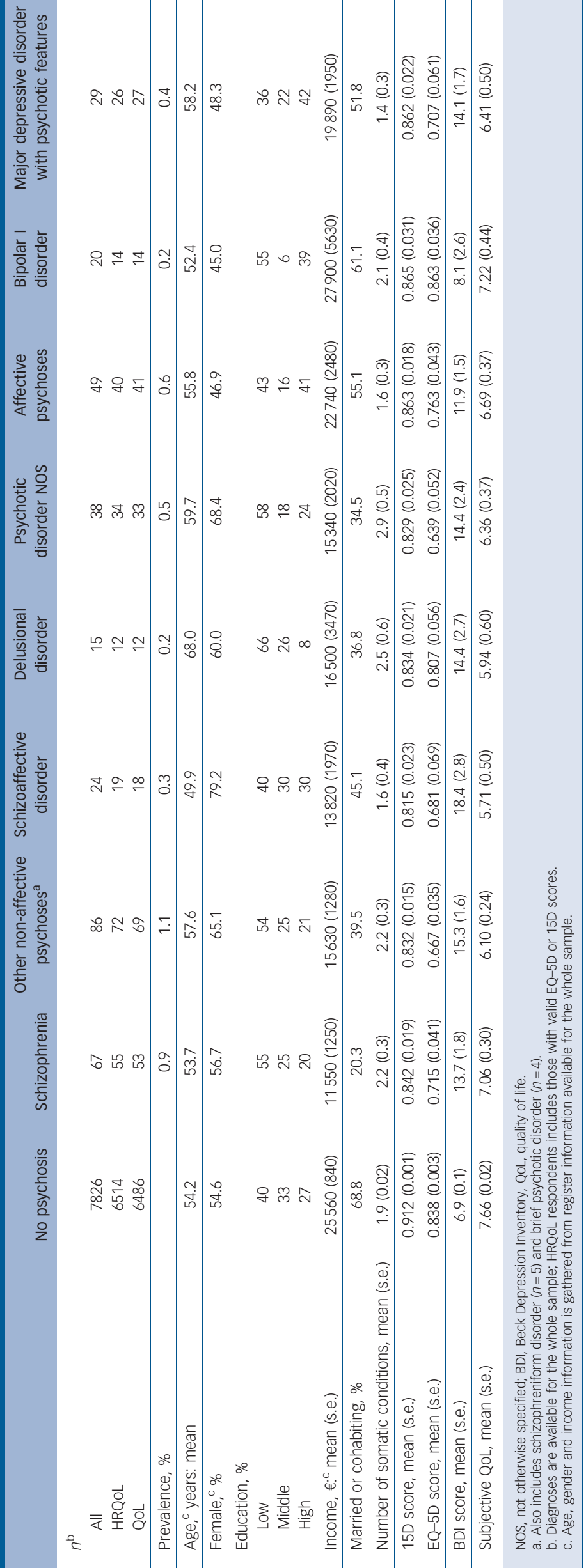

scored full health on EQ-D and $17.3 \%$ on $15 \mathrm{D}$ ) we used a Tobit model to account for this censoring. ${ }^{11,31,32}$ We report the marginal effects of the unconditional expected value of the HRQoL score, valued at the means of the explanatory variables. ${ }^{33}$ These marginal effects are interpreted comparably to beta-coefficients of linear regression, i.e. as the change in HRQoL score (health utility) associated with each psychotic disorder (adjusted for age or age and other covariates), compared with people without the disorder.

To investigate which dimensions of HRQoL were affected by schizophrenia, schizoaffective disorder and bipolar I disorder, we created $15 \mathrm{D}$ profiles using linear regression to adjust the losses on each 15D dimension for age and gender. As the 15D preference-based scoring system scales all dimensions between 0 and 1 , the losses are comparable. To investigate the correlations between QoL/HRQoL ratings and clinician-rated symptom severity and outcome, we calculated Spearman rank-order correlations as partial correlations, adjusting for age and gender. Regression analyses were conducted using Stata 8.2 for Windows, and the other analyses on SAS 9.1.3 on Windows. Analyses accounted for the two-stage sampling design. Post-stratification weights were used to correct for non-response (based on register information on the whole sample) and for oversampling of people aged over 80 years. $^{6}$

\section{Results}

\section{Background variables}

The sociodemographic characteristics of the sample, somatic conditions and BDI scores are presented in Table 1. People with non-affective psychoses were more often living alone, had lower education and less income than people with affective psychoses or the general population. Mean BDI scores were elevated (about 14-18) for all disorders except bipolar I disorder, where they were close to that of the general population.

\section{Analysis of non-response}

Response rates are presented in Table 1 (see online supplement for symptom-specific details). Briefly, QoL information was available for $85.1 \%$, EQ-5D for $78.5 \%$ and $15 \mathrm{D}$ for $80.2 \%$ of the sample.

\section{Loss of QOL/HRQOL in different disorders}

Unadjusted HRQoL and QoL scores are presented in Table 1, and adjusted scores in Tables 2 and 3. The results of only two models are presented in Table 3, as the results of the omitted models were essentially similar to the first model controlling only for age and gender.

Participants with non-affective psychoses other than schizophrenia had the lowest unadjusted HRQoL scores; their mean $15 \mathrm{D}$ score was 0.08 and EQ-5D score 0.17 points lower than the mean of the population without psychosis. For schizophrenia these differences were 0.07 and 0.12 respectively. When controlling for age and gender, schizophrenia, other non-affective psychosis and affective psychoses were all associated with decreases of $0.05-0.06$ points on the $15 \mathrm{D}$. On the EQ-5D, the decreases were 0.12 for schizophrenia, 0.11 for other non-affective psychosis and 0.06 for affective psychoses. Considering individual disorders, people with schizoaffective disorder had the largest age- and gender-adjusted losses of HRQoL: -0.09 on the 15D and -0.15 on the EQ $-5 \mathrm{D}$. Whereas all disorders were associated with statistically significant and clinically important decreases on the 15D, the EQ-5D did not detect any HRQoL losses for delusional or bipolar I disorders. 


\begin{tabular}{|c|c|c|c|}
\hline & Schizophrenia & Other non-affective psychosis & Affective psychosis \\
\hline $\begin{array}{l}\text { 15D HRQOL } \\
\text { Age and gender } \\
\text { + income, marital status, education } \\
\text { + somatic conditions } \\
\text { + Beck Depression Inventory }\end{array}$ & $\begin{array}{l}-0.056(-0.087 \text { to }-0.025)^{\star * *} \\
-0.043(-0.076 \text { to }-0.011)^{\star *} \\
-0.046(-0.073 \text { to }-0.019)^{\star *} \\
-0.027(-0.049 \text { to }-0.004)^{\star}\end{array}$ & $\begin{array}{l}-0.059(-0.082 \text { to }-0.036)^{\star * *} \\
-0.053(-0.075 \text { to }-0.031)^{* * *} \\
-0.051(-0.073 \text { to }-0.029)^{\star * *} \\
-0.012(-0.029 \text { to } 0.006)\end{array}$ & $\begin{array}{l}-0.048(-0.076 \text { to }-0.020)^{* *} \\
-0.046(-0.075 \text { to }-0.018) \\
-0.051(-0.080 \text { to }-0.022)^{\star *} \\
-0.022(-0.046 \text { to } 0.001)\end{array}$ \\
\hline $\begin{array}{l}\text { EQ - 5D HRQOL } \\
\quad \text { Age and gender } \\
\text { + income, marital status, education } \\
\text { + somatic conditions } \\
\text { + Beck Depression Inventory }\end{array}$ & $\begin{array}{l}-0.119(-0.176 \text { to }-0.062)^{\star * *} \\
-0.088(-0.146 \text { to }-0.029)^{* *} \\
-0.091(-0.156 \text { to }-0.026)^{\star *} \\
-0.043(-0.092 \text { to } 0.005)\end{array}$ & $\begin{array}{l}-0.113(-0.158 \text { to }-0.069)^{* * *} \\
-0.098(-0.140 \text { to }-0.055)^{* * *} \\
-0.090(-0.134 \text { to }-0.046)^{* * *} \\
-0.028(-0.071 \text { to } 0.015)\end{array}$ & $\begin{array}{l}-0.064(-0.127 \text { to }-0.001)^{*} \\
-0.068(-0.131 \text { to }-0.005)^{*} \\
-0.069(-0.129 \text { to }-0.009)^{*} \\
-0.020(-0.071 \text { to } 0.031)\end{array}$ \\
\hline $\begin{array}{l}\text { Subjective QoL } \\
\text { Age and gender } \\
\text { + income, marital status, education } \\
\text { + somatic conditions } \\
\text { + Beck Depression Inventory }\end{array}$ & $\begin{array}{l}-0.642(-1.232 \text { to }-0.052)^{*} \\
-0.247(-0.881 \text { to } 0.387) \\
-0.186(-0.798 \text { to } 0.426) \\
-0.096(-0.569 \text { to } 0.376)\end{array}$ & $\begin{array}{l}-1.437(-1.891 \text { to }-0.983)^{* * *} \\
-1.227(-1.664 \text { to }-0.790)^{* * *} \\
-1.216(-1.666 \text { to }-0.766)^{* * *} \\
-0.455(-0.868 \text { to }-0.043)^{*}\end{array}$ & $\begin{array}{l}-0.893(-1.617 \text { to }-0.169)^{*} \\
-0.835(-1.564 \text { to }-0.105)^{*} \\
-0.800(-1.456 \text { to }-0.144)^{*} \\
-0.305(-0.823 \text { to } 0.213)\end{array}$ \\
\hline
\end{tabular}

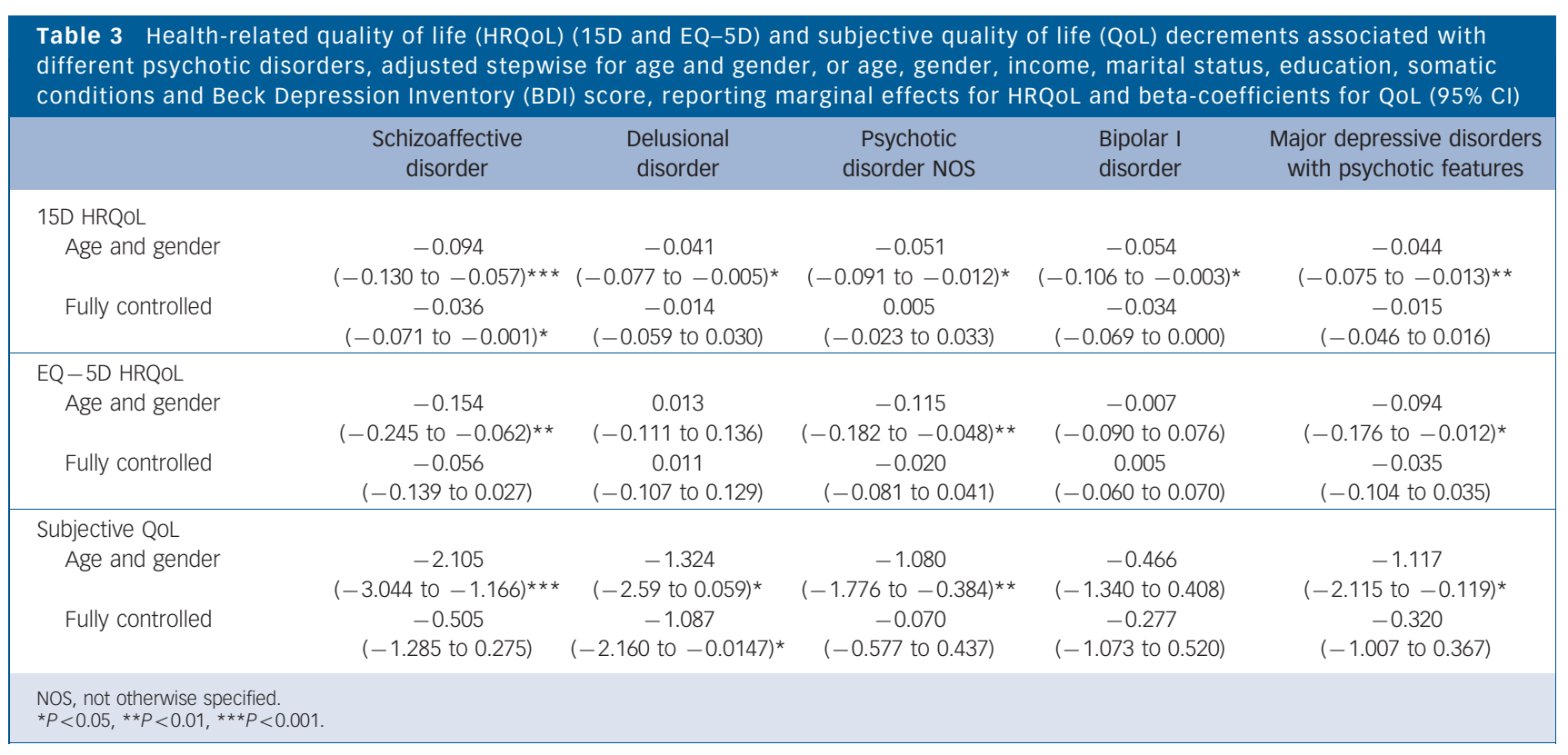

The other non-affective psychosis group also had the lowest unadjusted QoL scores: their mean QoL was 1.6 points below the population without psychosis, whereas this difference was 0.6 for schizophrenia. People in the other non-affective psychosis group also had the largest reductions of QoL in all the regression models. The schizophrenia group had statistically significant reductions of QoL when controlling for age and gender only, whereas the affective psychoses group fell between the other groups. Of individual disorders, people with schizoaffective disorder had the worst QoL, whereas those with bipolar I disorder did not have a statistically significant reduction of QoL.

\section{Effect of current depression}

The stepwise entering of socioeconomic variables and somatic conditions into regression models changed the HRQoL results relatively little. However, adding BDI score into the models mostly diminished the impact of disorders on HRQoL. Only schizophrenia and schizoaffective disorder were associated with statistically significant reductions of the $15 \mathrm{D}$ after controlling for the $\mathrm{BDI}$, whereas the $\mathrm{EQ}-5 \mathrm{D}$ detected no statistically significant effects of diagnoses after controlling for the BDI.

For QoL the picture was similar and the BDI explained most of the observed decreases, with two exceptions: for schizophrenia, socioeconomic variables explained most of the reduction of QoL. Delusional disorder was the only disorder where QoL was still statistically significantly reduced after controlling for the BDI.

\section{Dimensions of HRQOL influenced by different disorders}

The HRQoL profiles are presented in Fig. 1, in the form of age- and gender-adjusted decreases from population averages. The decreases were widespread for schizophrenia (11 of 15 dimensions statistically significantly decreased) and schizoaffective disorder (10 of 15) but less so for bipolar I disorder (3 of 15). 


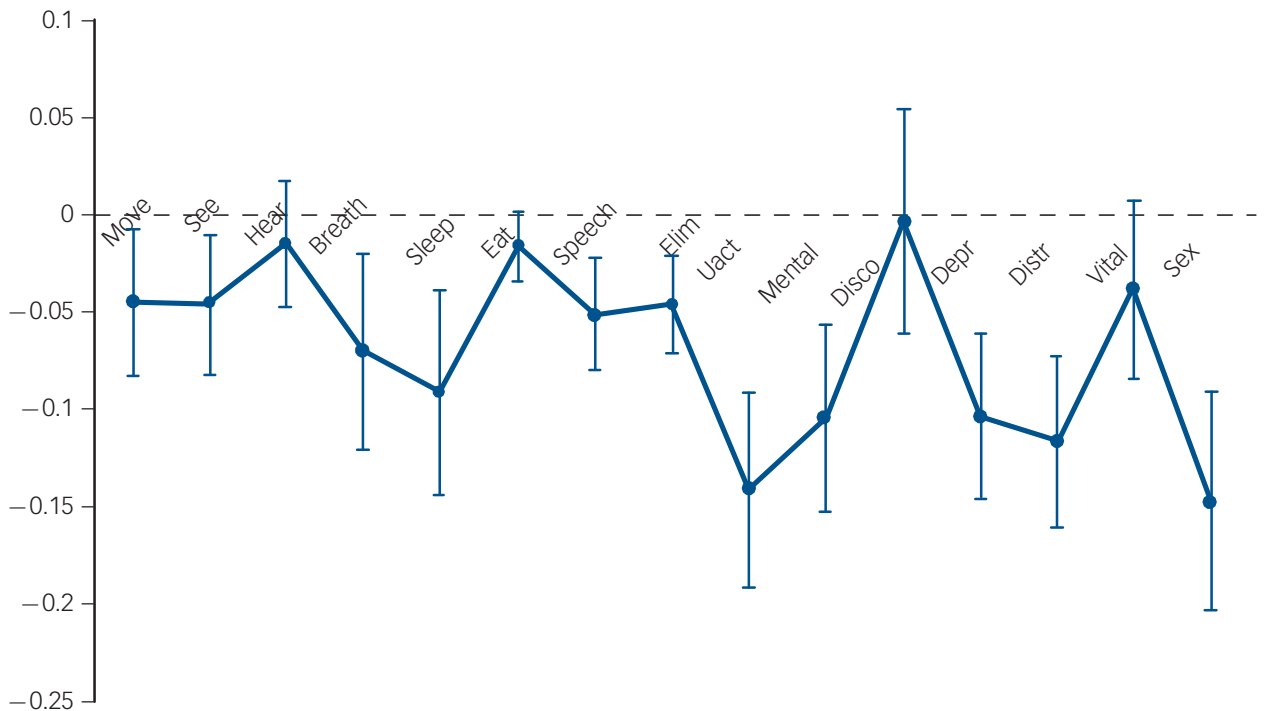

(b)

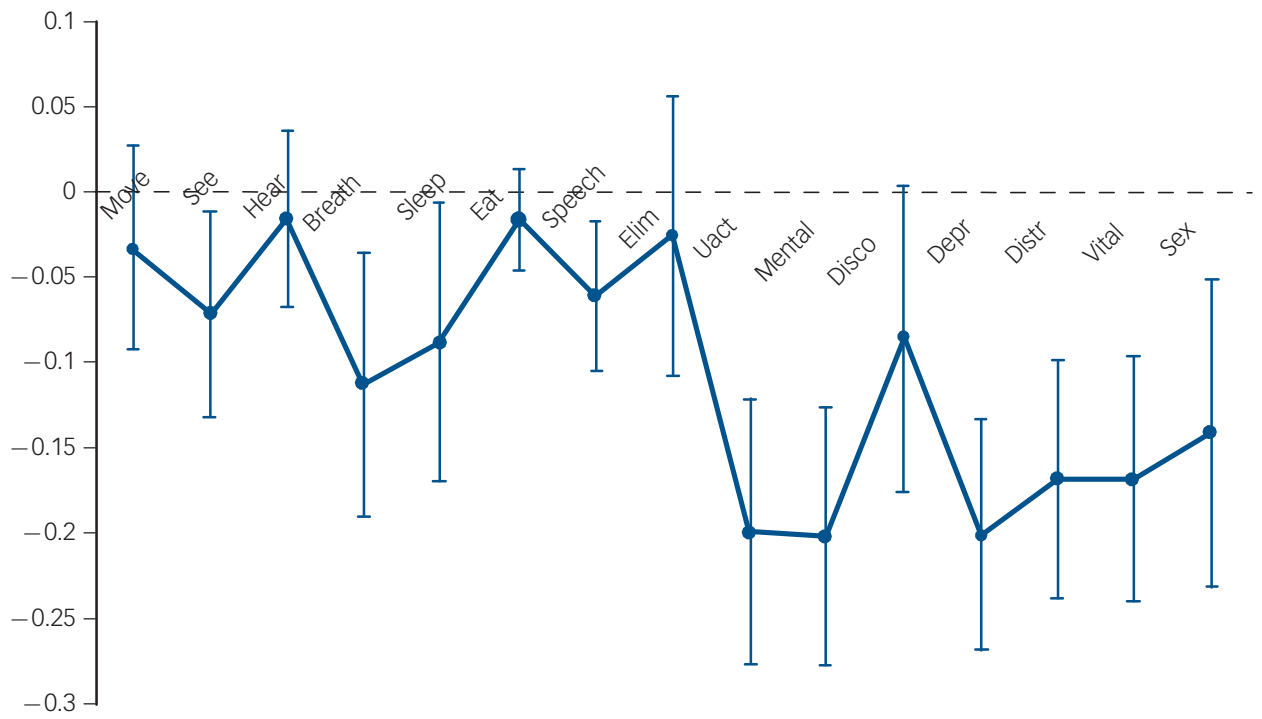

(C)

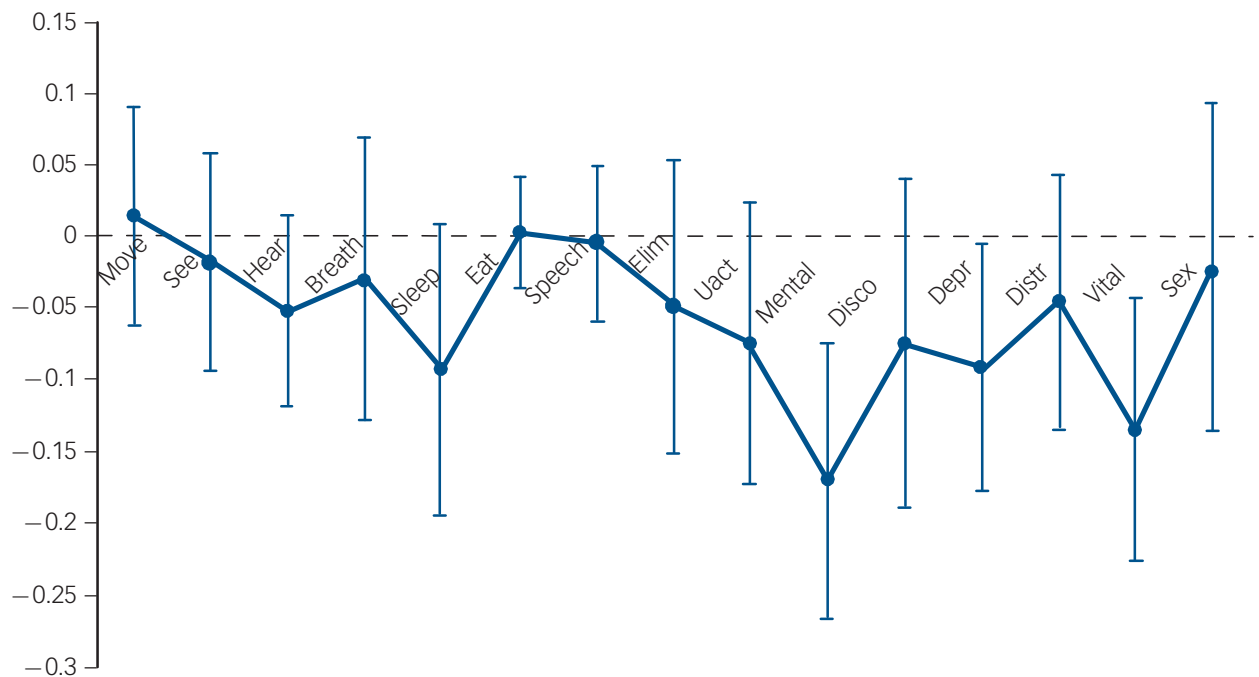

Fig. 1 Age- and gender-adjusted losses on different health-related quality of life (15D) dimensions with 95\% Cl. (a) Schizophrenia (b) schizoaffective disorder, (c) bipolar I disorder.

The 15 dimensions: Move, mobility; See, vision; Hear, hearing; Breath, breathing; Sleep, sleeping; Eat, eating; Speech, speaking; Elim, elimination; Uact, usual activity; Mental, mental function; Disco, discomfort and symptoms; Depr, depression; Distr, distress; Vital, vitality; Sex, sexuality. 


\section{Clinician-rated psychotic symptoms, outcome and QOL/HRQOL}

Online Table DS1 presents the Spearman correlations between QoL/HRQoL and lifetime ratings of positive, negative, disorganisation, depressive symptoms, course and outcome.

For all psychotic disorders combined, depressive and negative symptoms had small (0.1-0.3) correlations with QoL/HRQoL. Positive symptoms were not correlated with QoL/HRQoL. There was a trend for small positive correlations between mania, disorganisation symptoms and QoL/HRQoL, although this was statistically significant only for QoL and disorganisation. Clinician-rated course and outcome variables had small correlations with all QoL/HRQoL measures.

For schizophrenia, correlations were generally small and not statistically significant except for the correlation between depressive symptoms and QoL. For schizoaffective disorder, there were large $(<-0.5)$ negative correlations between negative symptoms, course, outcome and QoL/HRQoL measures. For delusional disorders, none of the correlations were statistically significant, although the correlation coefficients between course and especially the EQ-5D and QoL were large. For bipolar I disorder, negative correlations between depressive symptoms and HRQoL measures were large, and moderate $(-0.3$ to -0.5$)$ between depression and QoL. Correlations were positive although not statistically significant - between lifetime mania ratings and QoL/HRQoL scores. Negative correlations between course, outcome and QoL/HRQoL ratings were mostly moderate or large. For major depressive disorders with psychotic features, negative correlations were large for negative symptoms and the EQ-5D and QoL. Negative correlations between course, outcome and QoL/HRQoL ratings were mostly moderate or large.

\section{Discussion}

\section{Comparison with previous studies}

Our results can be compared with several types of studies: those studying the impact of psychotic disorders on health utility or subjective QoL; those comparing the impact of different psychotic disorders using almost any global outcome measure; and those studying the correlation of global outcomes and different symptomatic measures. As the main strength of our data is general population representativeness, we will concentrate here on studies comparing the severity of different disorders.

\section{Studies of health utility and psychotic disorders}

Our previous study comparing HRQoL in 29 psychiatric and somatic disorders showed that people with self-reported psychotic disorders ranked third in severity, after Parkinson's disease and major depressive disorder. ${ }^{11}$ Further examination of nonpsychotic disorders present within the past 12 months showed that HRQoL losses on the 15D (EQ-5D) were $-0.04(-0.07)$ for alcohol dependence, $-0.07(-0.13)$ for major depressive disorder and between -0.13 and $-0.14(-0.23$ and -0.27$)$ for dysthymia, social phobia, agoraphobia and generalised anxiety disorders. ${ }^{34}$ This puts the severity of lifetime schizoaffective disorder between 12-month major depressive disorder and anxiety disorders, and schizophrenia between 12-month major depressive disorder and alcohol dependence.

The Dutch Netherlands Mental Health Survey and Incidence Study (NEMESIS) originally showed that all 36-item Short Form Health Survey (SF-36) subscale scores for people with bipolar I disorder were lower than healthy controls. ${ }^{35}$ However, after a thorough diagnostic check (SCID-I), the remaining individuals with bipolar disorder did not differ from controls on the SF-36 or on the EQ-5D. ${ }^{36}$ This may have been as a result of the small sample size, as the EQ-5D score was 0.82 for the people with bipolar disorder and 0.88 for controls. Further, the response rate was only $47 \%$. Still, an EQ-5D value of 0.82 is clearly lower than that observed in our study, even though our participants with bipolar I disorder were 10 years older.

Generalisations from clinical studies are difficult, as the inclusion criteria vary and adjusting for age would be essential given that HRQoL decreases with age. ${ }^{11}$ Participants commonly report low HRQoL values: EQ-5D scores have been between 0.52 and 0.57 in recent studies of schizophrenia. ${ }^{37-39}$ These values are much lower than our results. Studies with people not actively seeking treatment have yielded results closer to ours. A UK study selecting stable out-patients obtained a EQ-5D value of $0.86 .{ }^{40} \mathrm{~A}$ German study of out-patients with non-affective psychoses (93\% schizophrenia or schizoaffective disorder) found a mean EQ-5D value of 0.71 . $^{41}$

In sum, this comparison emphasises the selected nature of participants seen in clinical trials that often recruit individuals who need some change of treatment. Care is needed when extrapolating from the results of clinical studies to population-level burden-of-disease estimations.

\section{Studies comparing different psychotic disorders on any QOL/HRQoL measures}

A review of the literature up to the year 2002 using a very wide conceptualisation of HRQoL (including, for example, Global Assessment of Functioning (GAF)) found 65 studies. ${ }^{42}$ Eight of the nine studies comparing bipolar disorder with schizophrenia suggested better HRQoL for people with bipolar disorder. Another review up to 2004 included 28 articles with five studies comparing bipolar disorder with other conditions. ${ }^{43}$ Most of these showed bipolar disorder to be comparable or milder than schizophrenia. Two studies suggested that the HRQoL of participants with bipolar disorder was equivalent to that of the general population.

In a US study on community-dwelling patients, no statistically significant differences were found between people with schizophrenia and bipolar I disorder on the Quality of Well-Being scale or SF-36. ${ }^{44}$ Another study comparing treatment-seeking individuals with bipolar I disorder and schizoaffective disorder found the EQ-5D scores of participants with bipolar to be significantly higher than those of participants with schizoaffective disorder (0.77 and 0.67 respectively). ${ }^{45}$ Participants with schizoaffective disorder had more depressive symptoms than the group with bipolar I disorder, in line with our results. A third study including out-patients with schizophrenia and schizoaffective disorder noted that those with schizoaffective disorder had significantly lower subjective QoL. ${ }^{5}$

Our results fit with the previous literature in suggesting that, on average, schizoaffective disorder is associated with more severe HRQoL impairment than schizophrenia. Bipolar I disorder has been associated with a smaller or similar HRQoL impact to schizophrenia, depending on the sample and the measures used.

\section{Studies of the association between symptoms, HRQOL and QoL}

In line with our findings, two previous schizophrenia studies found current depressive ${ }^{5}$ or depressive/anxiety ${ }^{4}$ symptoms to have the strongest correlation with QoL; correlations with positive, negative or disorganisation symptoms were not significant. One previous study investigating non-affective psychoses found EQ-5D to be correlated with positive and 
negative symptoms, but even then the strongest correlation was with depressive symptoms. ${ }^{41}$

For bipolar disorder, previous reviews of different phases of bipolar disorder have generally concluded that the HRQoL or QoL of people with bipolar disorder is lowered even in a euthymic phase, although clearly less so than in a manic phase. Depressive or mixed episodes are generally considered to be the worst, and current depressive symptomatology is a major predictor of lowered HRQoL. ${ }^{46}$ Results concerning the impact of the longitudinal course of bipolar disorder on HRQoL of currently euthymic patients are variable, ${ }^{43,44,47,48}$ but most studies have found that depressive symptoms are most strongly correlated with HRQoL and that they affect several domains of HRQoL. This fits well with our findings that the BDI score explains most of the lost HRQoL/QoL in bipolar disorder, and the lifetime severity of depressive symptoms strongly correlates with HRQoL.

\section{Validity of self-reported QOL and HRQOL}

Our study agrees with previous studies in showing that generic QoL/HRQoL instruments produce interesting but somewhat problematic results as outcome measures for psychotic disorders. They do not correlate well with all symptom dimensions or with clinician-assessed outcomes for all disorders, or with socioeconomic disadvantage. ${ }^{49}$ In contrast, current depression explains a major part of the loss in QoL/HRQoL. This poses a challenge for health-economic analyses of psychotic disorders: medical treatments commonly target positive symptom reduction, but their effect may go unnoticed when utility-based HRQoL is used as an outcome measure. The EQ-5D appears especially problematic. Disorder-specific measures should be used to complement generic HRQoL measures; in clinical use at least, depressive symptoms are likely to be better measured with depression scales than HRQoL instruments.

However, the alternative interpretation is also important to consider: as we used three different QoL/HRQoL measures, some construct validity of these instruments is likely. Previous studies converge in that depressive symptoms are extremely important for the subjective well-being of people with most psychiatric disorders. Our results show that people with schizophrenia have significant depressive symptoms that reduce their well-being substantially. Further, our results also offer some room for optimism concerning the QoL/HRQoL of people with bipolar disorder and schizophrenia. More general population studies are clearly needed.

The reliability of self-reports of people with psychotic disorders is sometimes questioned. Except for the most acute phases of illness, it has repeatedly been shown that people in stable phases of psychotic illnesses can assess their health states reasonably reliably and validly - even using cognitively demanding methods such as direct utility estimation. ${ }^{40,50}$ However, equally consistent is the finding that people with stable schizophrenia tend to rank their health utility higher than healthy people ${ }^{51}$ or professionals ${ }^{3}$ would. So, although our results suggest that people with common anxiety disorders and dysthymia rate their HRQoL lower than people with schizophrenia, bipolar disorder or even schizoaffective disorder, this must be interpreted in the light of larger socioeconomic disadvantage and loss of functioning associated with psychotic disorders. ${ }^{49,52,53}$

The aforementioned results - individuals reporting higher subjective well-being than professionals estimate or patients' actual functional status or socioeconomic circumstances suggests - provide caregivers with an ethical dilemma. If the higher valuations are not clearly 'flawed', i.e. caused by cognitive, affective or psychotic misunderstandings, they may still be caused by psychological adaptation to the condition and its limitations or lowered expectations. A theoretical key component to subjective QoL is the balance between expectations and opportunities. ${ }^{54}$ The ethical dilemma is to what extent the lowered expectations should be accepted? Taking at face value the high life satisfaction of people with psychoses appears problematic when objective indicators show great room for improvement. But excluding the subjective experience is also unacceptable.

\section{Strengths and weaknesses}

The significant strengths or our study are the use of a general population-based sample, the thorough diagnostics and the high participation rate. Our collection of case notes allowed us to compare the severity and symptoms of non-respondents with respondents. This revealed that people with more severe affective psychoses seemed to be somewhat underrepresented. On the other hand, people with the bipolar type of schizoaffective disorder were less likely to participate than those with the depressive type. These may have somewhat exaggerated our findings of the low burden of affective psychoses and the high burden of schizoaffective disorder, relative to schizophrenia. The group with delusional disorder was quite small. More general population studies that control for residual depressive symptoms are clearly needed.

It is important to emphasise that our results represent the individual disability and suffering of respondents. It thus underestimates the total burden of psychotic disorders because mortality and the burden on caregivers are not taken into account. A further possible source of underestimation is the age limit of our study. Psychotic disorders commonly have an onset before age 30, and the impact of psychoses may be relatively larger in young people when somatic conditions are rare and HRQoL usually high.

Depression had a large influence on HRQoL and QoL. Sociodemographic factors and chronic conditions had less influence than BDI score. However, as both the HRQoL measures used included questions relating to depression, this is also partly as a result of overlapping instruments. However, depression also affects subjective QoL and this supports the validity of this finding.

\section{Implications}

Schizoaffective disorder was associated with the lowest well-being in all measures used, followed by schizophrenia and bipolar I disorder. Schizophrenia and bipolar disorder were associated with a relatively larger loss of HRQoL than subjective QoL, whereas the contrary was true for delusional disorder and major depressive disorder with psychotic symptoms.

The results suggest that the subjective suffering reported by people with schizophrenia is smaller than the loss of objectively measured functioning. This discrepancy between self-reported well-being and functioning may be clinically relevant and also needs to be taken into account when HRQoL results are used for health policy or health economics purposes. The results also highlight the importance of minimising the side-effects of treatments, which may actually decrease health utility as much as the symptoms themselves. ${ }^{40}$

Current depressive symptoms explained most of the loss of HRQoL and QoL found. In particular, EQ-5D seems to be insensitive and measures mostly current depressive symptoms. Although depressive symptoms are important with regard to the well-being of people with psychotic disorders, this questions the utility of utility-based HRQoL measurements as sole outcome measures in psychotic disorders. 
Given that even participants with schizoaffective disorder had smaller HRQoL losses than people with dysthymia, generalised anxiety disorder, agoraphobia and social phobia, ${ }^{34}$ our results suggest some optimism concerning the subjective outcomes of psychotic disorders. However, although low QoL invites careful consideration of treatment alternatives, moderate subjective QoL does not warrant complacency in the treatment of psychotic disorders.

Samuli I. Saarni, MD, PhD, MSocSc, Department of Mental Health and Substance Abuse Services, National Institute for Health and Welfare, and the Department of Psychiatry, University of Helsinki and Helsinki University Central Hospital, Helsinki; Satu Viertiö, MSC, Jonna Perälä, MD, Department of Mental Health and Substance Abuse Services, National Institute for Health and Welfare, Helsinki; Seppo Koskinen $\mathrm{MD}, \mathrm{PhD}, \mathrm{MSOCSC}$, Department of Health, Functional Capacity and Welfare, National Institute for Health and Welfare, Helsinki; Jouko Lönnqvist MD, PhD, Department of Mental Health and Substance Abuse Services, National Institute for Health and Welfare, and the Department of Psychiatry, University of Helsinki and Helsinki University Central Hospital, Helsinki; Jaana Suvisaari, MD, PhD, Department of Mniversity Central Hoalth and Substance Abuse Services, National Institute for Health and Welfare, Helsinki, Finland

Correspondence: Samuli I. Saarni, MD, PhD, MSocSc, Department of Menta Health and Substance Abuse Services, National Institute for Health and Welfare, PO Box 30, 00270 Helsinki, Finland. Email: samuli.saarni@helsinki.fi

First received 10 Dec 2009, final revision 28 Feb 2010, accepted 15 Mar 2010

\section{References}

1 Rawlins MD, Culyer AJ. National Institute for Clinical Excellence and its value judgments. BMJ 2004; 329: 224-7.

2 Becker M, Diamond R. Quality of life measurement in persons with schizophrenia: are we measuring what's important. In Quality of Life in Mental Disorders, 2nd edn (eds H Katschnig, H Freeman \& N Sartorius). John Wiley \& Sons, 2006.

3 Herrman H, Hawthorne G, Thomas R. Quality of life assessment in people living with psychosis. Soc Psychiatry Psychiatr Epidemiol 2002; 37: 510-8.

4 Meijer CJ, Koeter MW, Sprangers MA, Schene AH. Predictors of general quality of life and the mediating role of health related quality of life in patients with schizophrenia. Soc Psychiatry Psychiatr Epidemiol 2009; 44 361-8.

5 Narvaez JM, Twamley EW, McKibbin CL, Heaton RK, Patterson TL. Subjective and objective quality of life in schizophrenia. Schizophr Res 2008; 98: 201-8.

6 Aromaa A, Koskinen S. Health and Functional Capacity in Finland. Baseline Results of the Health 2000 Health Examination Survey. Publications of the National Public Health Institute, 2004 (http://www.ktl.fi/attachments/suomi/ julkaisut/julkaisusarja_b/2004b12.pdf).

7 Wittchen $\mathrm{HU}$, Lachner G, Wunderlich $\mathrm{U}$, Pfister $\mathrm{H}$. Test-retest reliability of the computerized DSM-IV version of the Munich-Composite International Diagnostic Interview (M-CIDI). Soc Psychiatry Psychiatr Epidemiol 1998; 33: 568-78

8 Perälä J, Suvisaari J, Saarni SI, Kuoppasalmi K, Isometsä E, Pirkola S, et al. Lifetime prevalence of psychotic and bipolar I disorders in a general population. Arch Gen Psychiatry 2007; 64: 19-28.

9 First MB, Anthony JC, Tepper S, Dryman A. Structured Clinical Interview for DSM-IV Axis I Disorders, Research Version, Non-patient Edition (SCID-I/NP). Biometrics Research, New York State Psychiatric Institute, 1997.

10 Tengs TO, Wallace A. One thousand health-related quality-of-life estimates. Med Care 2000; 38: 583-637.

11 Saarni SI, Härkänen $T$, Sintonen $H$, Suvisaari J, Koskinen S, Aromaa A, et al. The Impact of 29 chronic conditions on health-related quality of life: a general population survey in Finland using 15D and EQ-5D. Qual Life Res 2006; 15: 1403-14.

12 The EuroQoL Group. EuroQol-a new facility for the measurement of healthrelated quality of life. Health Policy 1990; 16: 199-208.

13 Sintonen H. The 15D Measure of Health Related Quality of Life: Reliability, Validity and Sensitivity of its Health State Descriptive System. Working Paper 41. Centre for Health Program Evaluation, Monash University, 1994.

14 Dolan P. The measurement of health-related quality of life for use in resource allocation desicions in health care. In Handbook of Health Economics (eds AJ Culyer \& JP Newhouse): 1723-60. Elsevier, 2000.

15 Sintonen $\mathrm{H}$. The 15D Measure of Health Related Quality of Life. II Feasibility, Reliability and Validity of its Valuation System. Working Paper 42. Centre for Health Program Evaluation, Monash University, 1995.
16 Sintonen $\mathrm{H}$. The $15 \mathrm{D}$ instrument of health-related quality of life: properties and applications. Ann Med 2001; 33: 328-36.

17 Brooks R. EuroQol: the current state of play. Health Policy 1996; 37: 53-72. 18 Rabin R, de Charro F. EQ-5D: a measure of health status from the EuroQol Group. Ann Med 2001; 33: 337-40.

19 Kind P, Hardman G, Macran S. UK Population Norms for EQ-5D. Discussion Paper 172. Centre for Health Economics, University of York, 1999.

20 Walters SJ, Brazier JE. Comparison of the minimally important difference for two health state utility measures: EQ-5D and SF-6D. Qual Life Res 2005; 14: 1523-32.

21 Hawthorne G, Richardson J, Day NA. A comparison of the Assessment of Quality of Life (AQOL) with four other generic utility instruments. Ann Med 2001; 33: 358-70.

22 Stavem K, Bjornaes H, Lossius MI. Properties of the 15D and EQ-5D utility measures in a community sample of people with epilepsy. Epilepsy Res 2001; 44: $179-89$

23 Garratt A, Schmidt L, Mackintosh A, Fitzpatrick R. Quality of life measurement: bibliographic study of patient assessed health outcome measures. BMJ 2002; 324: 1417.

24 OECD. The OECD List of Social Indicators. Organisation for Economic Co-operation and Development, 1982.

25 Beck AT, Ward $\mathrm{CH}$, Mendelson $\mathrm{M}$, Mock J, Erbaugh J. An inventory for measuring depression. Arch Gen Psychiatry 1961; 4: 561-71.

26 Kendler KS, Karkowski LM, Walsh D. The structure of psychosis: latent class analysis of probands from the Roscommon Family Study. Arch Gen Psychiatry 1998; 55: 492-9.

27 Kendler KS, McGuire M, Gruenberg AM, O'Hare A, Spellman M, Walsh D. The Roscommon Family Study. I. Methods, diagnosis of probands, and risk of schizophrenia in relatives. Arch Gen Psychiatry 1993; 50: 527-40.

28 Andreasen NC. The Scale for the Assessment of Positive Symptoms (SAPS). The University of lowa, 1984

29 Andreasen NC. Negative symptoms in schizophrenia. Definition and reliability. Arch Gen Psychiatry. 1982; 39: 784-8.

30 Suvisaari J, Perälä J, Saarni SI, Juvonen $\mathrm{H}$, Tuulio-Henriksson A, Lönnqvist J. The epidemiology and descriptive and predictive validity of DSM-IV delusional disorder and subtypes of schizophrenia. Clin Schizophr Relat Psychoses 2009; 2: 289-97.

31 Austin PC, Escobar M, Kopec JA. The use of the Tobit model for analyzing measures of health status. Qual Life Res 2000; 9: 901-10.

32 Tobin J. Estimation of relationships for limited dependent variables. Econometrica 1958; 26: 24-36.

33 Cong R. Marginal effects for the Tobit model. Stata Techn Bull 2000: 27-34.

34 Saarni SI, Suvisaari J, Sintonen H, Pirkola S, Koskinen S, Aromaa A, et al. Impact of psychiatric disorders on health-related quality of life: general population survey. Br J Psychiatry 2007; 190: 326-32.

35 ten Have M, Vollebergh W, Bijl R, Nolen WA. Bipolar disorder in the general population in The Netherlands (prevalence, consequences and care utilisation): results from The Netherlands Mental Health Survey and Incidence Study (NEMESIS). J Affect Disord 2002; 68: 203-13.

36 Hakkaart-van Roijen L, Hoeijenbos MB, Regeer EJ, ten Have M, Nolen WA, Veraart $\mathrm{CP}$, et al. The societal costs and quality of life of patients suffering from bipolar disorder in the Netherlands. Acta Psychiatr Scand 2004; 110 383-92.

37 Davies LM, Barnes TR, Jones PB, Lewis S, Gaughran F, Hayhurst K, et al $A$ randomized controlled trial of the cost-utility of second-generation antipsychotics in people with psychosis and eligible for clozapine. Value Health 2008; 11: 549-62.

38 Knapp M, Windmeijer F, Brown J, Kontodimas S, Tzivelekis S, Haro JM, et al. Cost-utility analysis of treatment with olanzapine compared with other antipsychotic treatments in patients with schizophrenia in the pan-European SOHO study. Pharmacoeconomics 2008; 26: 341-58.

39 Prieto L, Sacristan JA, Hormaechea JA, Casado A, Badia X, Gomez JC. Psychometric validation of a generic health-related quality of life measure (EQ-5D) in a sample of schizophrenic patients. Curr Med Res Opin 2004; 20: 827-35.

40 Briggs A, Wild D, Lees M, Reaney M, Dursun S, Parry D, et al. Impact of schizophrenia and schizophrenia treatment-related adverse events on quality of life: direct utility elicitation. Health Qual Life Outcomes 2008; 6: 105.

41 Konig HH, Roick C, Angermeyer MC. Validity of the EQ-5D in assessing and valuing health status in patients with schizophrenic, schizotypal or delusional disorders. Eur Psychiatry 2007; 22: 177-87.

42 Dean BB, Gerner D, Gerner RH. A systematic review evaluating health-related quality of life, work impairment, and healthcare costs and utilization in bipolar disorder. Curr Med Res Opin 2004; 20: 139-54. 
43 Michalak EE, Yatham LN, Lam RW. Quality of life in bipolar disorder: a review of the literature. Health Qual Life Outcomes 2005; 3: 72.

44 Depp CA, Davis CE, Mittal D, Patterson TL, Jeste DV. Health-related quality of life and functioning of middle-aged and elderly adults with bipolar disorder. J Clin Psychiatry 2006; 67: 215-21.

45 Kulkarni J, Berk M, Fitzgerald PB, de Castella AR, Montgomery W, Kelin K, et al. The Bipolar Comprehensive Outcomes Study (BCOS): baseline findings of an Australian cohort study. J Affect Disord 2008; 107: 135-44.

46 Namjoshi MA, Buesching DP. A review of the health-related quality of life literature in bipolar disorder. Qual Life Res 2001; 10: 105-15.

47 Ozer S, Ulusahin A, Batur S, Kabakci E, Saka MC. Outcome measures of interepisode bipolar patients in a Turkish sample. Soc Psychiatry Psychiatr Epidemiol 2002; 37: 31-7

48 MacQueen GM, Young LT, Robb JC, Marriott M, cooke RG, Joffe RT. Effect of number of episodes on wellbeing and functioning of patients with bipolar disorder. Acta Psychiatr Scand 2000; 101: 374-81.
49 Perala J, Saarni SI, Ostamo A, Pirkola S, Haukka J, Harkanen T, et al Geographic variation and sociodemographic characteristics of psychotic disorders in Finland. Schizophr Res 2008; 106: 337-47.

50 Voruganti LN, Awad AG, Oyewumi LK, Cortese L, Zirul S, Dhawan R. Assessing health utilities in schizophrenia. A feasibility study. Pharmacoeconomics 2000; 17: 273-86.

51 Fan $X$, Henderson DC, Chiang E, Briggs LB, Freudenreich O, Evins AE, et al. Sexual functioning, psychopathology and quality of life in patients with schizophrenia. Schizophr Res 2007; 94: 119-27.

52 Viertio S, Sainio P, Koskinen S, Perala J, Saarni SI, Sihvonen M, et al. Mobility limitations in persons with psychotic disorder: findings from a populationbased survey. Soc Psychiatry Psychiatr Epidemiol 2009; 44: 325-32.

53 Pirkola SP, Isometsa E, Suvisaari J, Aro $\mathrm{H}$, Joukamaa M, Poikolainen $\mathrm{K}$, et al. DSM-IV mood-, anxiety- and alcohol use disorders and their comorbidity in the Finnish general population. Results from the Health 2000 Study. SOC Psychiatry Psychiatr Epidemiol 2005; 40: 1-10.

54 Calman KC. Quality of life in cancer patients-a hypothesis. J Med Ethics 1984 10: $124-7$.

\section{psychiatrists}

in 19th-century fiction

\section{Shirley Hall Asylum: Or the Memoirs of a Monomaniac (1863)}

\section{by William Gilbert (1804-1890)}

\section{Fiona Subotsky}

William Gilbert, another medical author, was the father of a more famous son, W. S. Gilbert, the dramatist and librettist. The former wrote a number of non-fiction works, usually concerned with the conditions of the poor, and then achieved considerable success with the novel Shirley Hall Asylum, told from the point of view of a lunatic.

The narrator does not consider himself to be insane, but merely overstressed by the problems and expense of inventing a perpetual motion device, first for ships and then for locomotives. He settles in at Shirley Hall, a private asylum with two buildings, one for the seriously ill, the other for people who appear at first acquaintance to be well, but later turn out to be 'monomaniacs'. In charge is the assistant physician Dr Meadows, a 'talented, amiable man, [who] treated those whose misfortunes had placed them under his care with the greatest skill, kindness, and consideration.' He tries, in the best fashion of the time, to treat his well-bred patients as guests, or part of a family. In the narrator's view, however, the doctor is no less a monomaniac, being obsessed with building and improving an organ, which is gradually taking over his study.

The doctor and the narrator are soon on good terms, which provides the opportunity for recounting the stories of many of the patients, mostly somewhat absurd, even though the symptoms have frequently been triggered by bereavement. Indeed, the general tone seems to be set by one of the inmates, labelled 'the cynic', who is unable to control his urge for mockery because of a lifetime of minor disappointments.

Eventually Dr Meadows' good humour deserts him, as the requirements of his hobby outpace his income: 'from being excessively courteous and patient, he became extremely caustic and irritable'. The narrator leads an unsuccessful patient revolt, and then decides to escape. While at large, however, he becomes depressed at the feats of the spiritualist levitator Mr Home, whose command of mechanical forces seems so much greater than his own. He concludes that this must be Satanic and, convinced Home is pursuing him, he takes refuge in another asylum. The reader is not informed of the fate of Dr Meadows.

Harrington Tuke, writing on 'Monomania' in this Journal's predecessor in 1867, clarified that the term, coined by Esquirol, was etymologically misleading: it was generally applied to cases of partial insanity including melancholia. Cases of a single fixed delusion, with cheerfulness, were rare but could include 'believers in the ghostly power of Hume [sic]', though this was not necessarily a sign of disease. Dr Gilbert clearly preferred the popular to the medical view. 